\title{
Risk Factors of the Partner Relationship between Open Source ERP Editors and IT Services Companies
}

\author{
Balla Diop ${ }^{1}$, Daniel Pascot ${ }^{1}$, Sidi Mahmoud Aidara Mbibi ${ }^{1} \&$ Louis-Claude Banag ${ }^{2}$ \\ ${ }^{1}$ Centre de recherche et de transfert en architecture d'entreprise (CeRTAE), Département des systèmes \\ d'information organisationnels, Faculté des sciences de l'administration, Université Laval, Pavillon \\ Palasis-Prince, Canada \\ ${ }^{2}$ African Aid Organization, Inc. (AFAID) \\ Corresponding: Balla Diop, Centre de recherche et de transfert en architecture d'entreprise (CeRTAE), \\ Département des systèmes d'information organisationnels, Faculté des sciences de l'administration, Université \\ Laval, Pavillon Palasis-Prince, 2325, rue de la Terrasse, local 2653, Québec (Québec) G1V 0A6, Canada. \\ Tel.:1-418-6562131 ext 8193. E-mai: balla.diop@fsa.ulaval.ca
}

Received: September 17, 2012 Accepted: October 11, $2012 \quad$ Online Published: August 20, 2013

doi:10.5539/ibr.v6n9p44 URL: http://dx.doi.org/10.5539/ibr.v6n9p44

\begin{abstract}
The open source ERP systems are beginning to take a significant market share of ERP in SMEs. They are supported and developed by several actors: open source editors and communities. The purpose of this study is to examine the risk factors in the relationship of open source ERP editors and their partners (i.e., the information technology (IT) services companies). Three exploratory case studies on partnership relations between ERP editors and IT services companies are carried out by relying on a qualitative method of collecting and analyzing data. The results show the existence of several of risks in such a relationship: the risk of fork, the risk of opportunistic behavior, the risk of conflict, the risk of absorption, the risk of non-appropriation, and finally the risk differences of objectives. These results confirm the risk factors already found in the literature in strategic alliances. This research is based on a qualitative approach, therefore reducing its generalization. In terms of managerial implications, this research creates awareness among leaders of IT services companies, who wish to become a partner of ERP open source editor, to the risks involved in such collaboration. Open source Software and particularly open source ERP systems are a modern phenomenon. This paper examines the relationship between open source ERP editors and their partners in terms of risk, whereas the literature on risk factors focuses only in the world of proprietary software (or commercial).
\end{abstract}

Keywords: partnership, risk factors, open source ERP, open source ERP editor

\section{Introduction}

The industry of enterprise systems (e.g., ERP, CRM, SCM, etc.) was until the early 2000s, dominated by proprietary enterprise systems. The emergence of free software especially the emergence of open source enterprise systems (open source ERP systems, open source CRM systems, open source SCM systems) have radically changed the industry to the point of upsetting. The supremacy of proprietary enterprise systems developed by private firms is threatened as never before. This threat is much more pronounced in the market for ERP systems. The editors of proprietary ERP systems (e.g., Microsoft Dynamics, Baan, SAP, etc.) are threatened by new players: open source ERP systems editors. The diffusion of open source ERP systems (e.g., OpenERP, OpenBravo, Compiere, Adempiere, ERP5, etc.) to SMEs has done in an exponential way and several reasons can explain it. Considering this new market niche (i.e., the growing number of SMEs adopting open source ERP systems), many software companies have changed their business model to include specialized services for the implementation of these. As in the proprietary or commercial world, the competition is also dense in the open source world especially in the world of open source ERP systems where several open source editors compete for market shares. Some of open source ERP editors are making their expansion strategies by basing on the principle of partnership with IT companies to increase the number of implementation among SMEs. In the long term, this strategy can play positively on their dominance or reputation in this sector. However, frustrations of the partners (i.e., the IT services companies) associated with open source editors begin to echo some slippage committed by some open source ERP editors. 
Several studies in the field of IT have investigated, the one hand, the relationship between editors and consulting companies in the context of proprietary software and, on the other hand, the risks involved in the implementation of information technology or information systems (IT/IS). However, these studies were only made in the world of proprietary/commercial software. Therefore, results or experiences learned in the research carried out in the world of proprietary software could not be extended or deducted directly to the context of the open source since several characteristics differentiate the contexts of open source software and proprietary software. Unlike the context of proprietary software that has been subject of several studies, researches on the context of open source are fewer because they are a contemporary phenomenon. The specifics of open source context should be explored to better understand them. Free/open source communities, supporting the development of open source software, have specific values and ethical standards regarding the vision of sharing information resources. Moreover they have their own modes of operation, working and organization methods (Lerner \& Tirole, 2003). Thus, the developments of open source software are support by several actors who can be either active or passive. These actors, from different horizons and with different objectives, pool their resources and work together to develop open source software. Therefore, these collaborative relationships, often in the form of partnership, are still a mystery to the scientific community and should be studied to further our knowledge in the world of open source software. For this purpose the objective of this paper is to study the risk factors in the relationship between open Source editors and their business partners.

This article is organized as follows. First, we describe the open source ERP systems and relationships of open source ERP editors. And then we present the research methodology used. Then we report the results, including discussion of key risk factors that partners open source ERP editors are exposed. Finally, we present some conclusions, including limitations and future directions of research.

\section{The Context of the Development of Open Source ERP}

Open source ERP systems are free software (i.e., software developed by open source communities). To better understand the differences between open source ERP systems and proprietary ERP systems, it is important to focus on the fundamental differences between these two types of software. Multiple expressions or terms are used to refer to the phenomenon of open source software, it is including Free Software (FS), in reference to the Free Software Foundation, Open Source Software (OSS) in reference to the initiative open source of Free open Source Software (FOSS), of Free/Libre/Open source Software (FLOSS) or Free Software (LS) (Sowe et al., 2008; Halilem \& Diop, 2008). We use the concept of free software or open source to refer the software developed by open source communities. Unlike proprietary software that are closed programs, most open source software have a large amount of information available to the public: the source code of the program, the participation of community members in the analysis and design of the program, discussions between developers on the project design and future directions, discussions between users and developers on how the software works (Bouras et al., 2012). The fundamental difference between proprietary software and open source software are mainly on the difference in rights of freedom possessed by the users. Users of open source software have four fundamental rights: (1) the right to use the software, (2) the right to copy the software, (3) the rights to study the program, (4) the right to modify the software and redistribute the modified versions. Thus, an open source ERP system is an ERP system whose source code is accessible by all users. An ERP system is a set of software modules so that each covers a specific functional and all the modules share a single common database (Xue et al., 2005). ERP systems are designed to integrate and optimize organizational business processes (Motwani et al., 2005).

The scientific community attaches great importance to open source software because: (1) the adoption of open source software by private and public organizations continues to increase year after year, (2) the significant investment provided by large software firms (e.g., HP, IBM, Red Hat, Cobalt Network, Google, etc.) to support the development of open source software. Dedrick and West (2004) attribute the success of open source software in their new approach to work: a virtual horizontal organizational structure based on merit and, also, a gentle and agile management. Until the past not too far, the ERP market was especially populated by proprietary ERP systems such as SAP, Oracle, Microsoft Dynamics, Baan, etc. But these proprietary systems posed some problems of rigidity, even though they often answer appropriately to the needs of integration and management of business processes of organizations. The rapid expansion of open source ERP, since their emergence, promises a difficult future for proprietary ERP (i.e., the proprietary ERP editors). Thus, access to source code and low cost procurement of open source ERP were decisive factors in their adoption of SME.

\subsection{Partnerships of Open Source ERP Editors and IT Service Companies}

Given the talent and expertise, which are abound in open source communities, many companies have decided to 
take advantage of this human capital by placing their proprietary software under public license, in other words, by giving their software to open source communities. For example, we can cite the case of the Netscape web browser who became Mozilla (Lerner \& Tirole, 2003). Several private editors, who struggled to raise their proprietary software, are now using the open source communities to support the development of their software. This strategy seems to work well and looks like a form of outsourcing their software development to the open source communities. However, companies, by giving their software to open source communities by the release of the source code, create other control mechanisms and management of their given or released software support by the open source communities. They create organizations or foundations responsible for managing the evolution of their (open source) software development. These types of organizations allow editors to maintain control of their development project supported by the open source software community. As emphasized Von Krogh and Spaeth (2007), companies can finance certain development projects of open source software in the same way they could fund research projects in the private sector. But, the vision of financial profitability of these private companies working with the open source communities for the development of their products has not changed. According to Bonaccorsi et al. (2006), these companies, with hybrid business models, collaborate with the open source community in order to reduce the wage costs and to ensure the development and evolution of their (open source) software, in long term. Also, they establish some business partnerships with IT services companies (ISC) to popularize and propagate their applications in order to achieve financial gain. In the context of open source software, firms maximize their profits through the sale of services. This is the case of ERP open source systems because the cost of acquiring an open source ERP is negligible. Thus, most software is adopted and most the support service of this software is high. Companies release their sources codes of their application in order to attract more skilled developers. Thus, the number of programmers supporting the development of software plays an important role in the development and evolution of the (open source) software (West, 2003; Lerner \& Tirole, 2003).

Some open source ERP editors are making their expansion strategies based on the principle of partnership with IT services companies to increase the number of implementation of their applications for SMEs. This may in the long term play on the reputation of their open ERP system, because there are more than a dozen open source ERP systems supported by open source communities. The number of partnership open source ERP editors (in this case, OpenERP, OpenBravo, Compiere, Adempiere, ERP5, etc.) is increasing. Some open source ERP editors have more than 400 partners around the world. Thus, with the rise of open source software in all spheres of our society, many IT companies have integrated open source software in their business model. Some of them have established partnerships with open source ERP editors and then become representatives of the open source ERP editors. However, like any collaborative relationship, there are advantages and disadvantages as well as challenges. Dahlander and Magnusson (2005), with a qualitative approach, studied the relationship between hybrid businesses and the open source communities. They developed a description of the different types of relationships that (commercial) companies can develop with open source communities. These authors identified three types of relationships between a company (private sector) and open source communities: (1) symbiotic relationships, (2) relationships of commensal type, (3) relationships of parasite type.

The research of Dahlander and Magnusson (2005) concerns only the relationship between the (commercial) enterprises and open source communities. The relationship between companies (such as open source ERP editors) and their partners (in this case of IT services companies) has not yet received much attention of the scientific community. No research has yet studied the risks faced by IT service companies in their relationship with the open source ERP editors. In this present study, we investigate the other side of the relation of partnership of open source ERP systems editors, i.e., we look at the risks in relations between open source ERP editors and the business world (especially with their partners in the private world).

\section{Risks Involved in a Partnership Relation}

Collaborative and partnership relation in the context of IT project have been studied in several facets. Bitner et al. (1990) studied the determinants of positive and negative events in the context of a service relationship. Claybaugh and Srite (2009) studied the positive and negative determinants in the relationship of IT editors and their customers. Many explanatory models of collaborative relationships have been proposed in the literature. The scientific community has always had an interest in studying the partnership or collaborative relationships in the IT industry especially in IT projects to better understand the key factors of IT projects' success where several stakeholders work together. The relationship between open source ERP editors and their partners has risks like any other partnership relation. For most collaboration, the partners may be exposed to various risks such as the non-performance and relational risk. The latter may result from opportunistic behavior and can be defined as the probability of an undesirable behavior (Poba-Nzaou et al., 2008; Das \& Teng 1996). The literature on risk is 
abundant and several areas (management, information systems, finance, joint-venture, strategic alliances) have studied the concept of risk and its dimensions. Miller (1992) proposed a typology of risk into three categories: (1) the risks specific to firms, (2) the risks to the environment, (3) risks related to the business.

The literature showed several risks that partners of a relationship may be exposed : the risk of non-appropriation (Kale et al, 2000), the risk of absorption (Hagedoorn \& Sadowski, 1999), the risk of rigidity (Young-Ybarra \& Wiersema, 1999), the risk of conflict (Zaheer et al., 1998), the risk of misunderstanding (Doz, 1996), the risk of problems contribution and retribution (Brockhoff, 1992), the risk of costs problems (Brockhoff, 1992), the risk of defection (Nooteboom et al., 1997), the risk of opportunistic behavior (Parkhe, 1993), the risk of dependence (Williamson, 1991), the risk of leakage of skills (Kale et al., 2000), the risk of conflicting objectives (Hagedoorn \& Sadowski, 1999) and, finally, the risk of lack of transparency of one partner. In a project of information technology or information systems (IT/IS) where many stakeholders with different personal goals have to collaborate together, there may also be risks of organizational, technological, contractual, financial, entrepreneurial and managerial (Poba-Nzaou et al., 2008). The relationships between the stakeholders or actors in IT/ IS project are similar to the relationship between the open source ERP editors and their partners, as they are all partnership relations. Like any alliance, these relationships are probably facing the same issues precisely to the same risks. The literature in the IT field raised several risks related to IT/IS projects. During the implementation of a complex IT/ IS like projects of enterprise systems (i.e., ERP, CRM, SCM), several risks may appear: low quality system, overspending, exceeding the delivery time, user dissatisfaction, discontinuation of project (Besson, 1999). In a complex IT/IS projects like the projects of developing or implanting an ERP systems, there may be three possible outcomes: (1) complete failure (i.e., an abandoned initiative); (2) partial failure (i.e., the main objectives are not met or there are significant adverse consequences); (3) success (i.e. the main objectives of most stakeholder groups are being met or although these groups have not suffered to undesirable consequences) (Heeks, 2002). With a literature review of risk, Aloini et al. (2007) identified the main risks associated with complex IT projects: (1) over budget, (2) timeout, (3) halting the project., (4) poor business performance, (5) lack of reliability and stability of the system, (6) low alignment of organizational processes, (7) low usability, (8) low degree of integration and flexibility, (9) weak strategic goals, (10) poor financial/economic performance. Given the exposure of risks in a partnership relation in an IS/IT project, it is important to study the key risks in the relationship between the open source ERP editors and their partners.

\section{Methodology}

In a keynote address at Gartner Open Source Summit 2007, Mark Driver, Research Vice President of Gartner, noted that by 2011 at least $80 \%$ of commercial software packages will contain open-source code (Brodkin, 2007). The Free/Open Source software (F/OSS) movement has not only revolutionized the industry of IT and software, but it has changed the business model of IT companies. During the last decade, the expansion of open source software particularly the breakthrough of the Open source ERP software has been remarkable. The market share of Open source ERP system continues to increase. Open source ERP have become major competitors for commercial ERP. This rapid expansion is due in part to the multiple partnership relations established by the open source ERP editors with IT service companies acting as representatives and commercial agents. These IT services companies help SMEs implement their open source ERP systems and, one side, they are members of the community supporting the development of the ERP system. They support the development of these systems by contributing to the development of codes or modules or by bringing improvements on the application. The number of implantations of ERP open source continues to grow in the market of SME, what motivates open source ERP editors to collaborate with more IT service companies in order to increase the adoption of their open source ERP. As with any relationship, the sustainability of these relationships between open source ERP editors and their partners may be compromised in the future by various risks. Thus, we considered important to examine the risk factors with respect to partnership relations of open source ERP editors and their partners. Given the lack of literature on this specific topic, the case study was selected as the best way to get maximum knowledge and understanding on the issues of relationships in the world of F/OSS. The objective of this study is to explore the different risks factors that the relations of open source ERP editors and their partners can be exposed. Following Eisenhardt (1989), and Yin (2009), case research is employed to answer the question: what are the risk factors that may affect the relationship between an editor of open source ERP and its partners

F/OSS movement is a contemporary phenomenon. According to Metaxiotis (2009), the ERP system is a contemporary technology. The open source ERP has appeared recently in the world of open source software. According to several researchers (Yin, 2009; Berrios \& Lucca, 2006), a case study is an empirical inquiry that investigates a contemporary phenomenon within its real-life context, especially when the boundaries between phenomenon and context are not clearly evident. The case study is an appropriate strategy to address any 
questions related to organizational and social regarding the development of an information system (IS), the implementation and use of IS (Darke et al., 1998) because of the potential of detailed that can be collected (Mabert et al., 2003) information. The main goal of our research is to examine the risk factors in the partnership relations of open source ERP editor and their partners (IT companies associated). Therefore, we study a relational dimension to the partnership of the open source editor and their partners. Thus, the development of open source ERP and context to the study (i.e., the risk factors of partnership relations of open source ERP editors and their partners) are inextricable because the purpose of such collaboration is to support the development of the open source ERP system through the development of new modules or debugging. Consequently, it is difficult to delineate a separating line between ERP and context (i.e., the risks factors). Taking into account the conditions (or elements) suggested by Yin (2009), it is obvious that the case study method is the research strategy the most appropriate in our research. First, we visited various sites of open source ERP editors: Openbravo, OpenERP, Compiere, Adempiere, ERP5, etc. From their websites, we got a list of several. We selected only the partners located in French context (i.e., Canada, France, Belgium, etc.) and we built a database composed of 100 partners. We contacted by email these partners to invite them to participate in this study. Three of them have responded favorably to participate in our study. To ensure anonymity, the search results are presented as summaries of findings named A, B and C involved in the case study companies. The main form of data collection was in-depth interviews conducted with leaders of the IT services companies. An interview guide was developed and open-ended questions were used throughout the interviews. Data collection lasted a month. The questions were derived from previous studies on risk factors in relationships especially in the context of the implementation and development of an IS/IT. Each semi-structured interview lasted 30-60 min. Interviews. To help ensure the validity and reliability of the assessment, we established a case study protocol. The protocol includes a case study database that consists of case study notes, tabular materials, case study documents and a case study narrative. The interviews were tape-recorded. In order to minimize bias that the researchers might introduce into the process of analyzing findings, a rigorous and structured approach to analysis was followed (Yin, 1989). For example, the interviewer took notes and taped each interview. There are several qualitative data analysis software packages available today (e.g., QDA Miner, Nvivo, etc). For this study, we have used QDA Miner for three very practical reasons. First, the design of QDA Miner is very simple to use. The software is specifically helpful in the coding and, ultimately, in helping to draw relationships between categories and the developing pattern. The companies $\mathrm{A}, \mathrm{B}$ and $\mathrm{C}$ provided documentations on their ERP projects. In addition, the public information regarding each company was collected from the Internet. Based on the data gathered from these multiple sources, two of the authors first performed analyses independently and examined the cases for evidence relevant to risk factors. The evidence was summarized and categorized. Two authors' case analyses were compared, and they were also reviewed by another author who offered complementary comments. Through debate, discrepancies between the two analyses were resolved and referencing back to the case data.

\section{Findings}

Data analysis was performed on the basis of a coding of all interviews and then a thematic content analysis (Miles \& Huberman, 2003). Analysis of the data, specifically, coding interviews was done with the support of QDA Miner software, according to a dictionary of topics including more than a dozen codes. Double coding was done to ensure the reliability of this stage of data analysis. The method used in the data analysis is content analysis. The analysis of case data is based on Miles and Huberman (1994), consisting of three analytical activities: 1) data reduction, 2) data display, 3) the development of verification table's conclusions. Companies A, $\mathrm{B}, \mathrm{C}$ are partners with the same editor open source ERP for more than 3 years. Those are all, IT service companies and have more than ten years of experience in IT sector. These companies have a variety of computer skills. All three companies have included F/OSS in their business model. Analyses of verbatim of these three cases have revealed several risks:

\subsection{Risk of Fork}

Bifurcation, commonly known as "forking", is the division of a project into two branches (example: Adempiere and Compiere case). Bifurcation occurs when members of a community stop sharing the same objectives or vision and that a group of programmers decide to split up from the original group to develop the software according to its objectives. Companies A, B, C have all raised the risk of bifurcation of the ERP system they support with the open source community and open ERP editor source. The reasons for bifurcation are many and vary from case to case. According to respondents, the constant change of the business model of open ERP editor source raises partners' frustrations. The frustrations are also caused by the fact that the ERP open source editor monitors the development of ERP system open source without involving senior partners in the important decision-making process. Partners deplore such a practice from the editor of ERP system open source, which increases the frustrations of the partners 
as well as other members of the open source community. This increases the risk of splitting the community, which means the risk of bifurcation. The following excerpts of the verbatim reflect the frustrations of the partners:

"Given the increasingly growing frustrations among partners, there is indeed a risk of division"

"The Editor takes insensitive measures to try to ensure recurring revenues, asymmetrically".

\subsection{Risk of Opportunistic Behavior}

All three companies $(\mathrm{A}, \mathrm{B}, \mathrm{C})$ have reproved the opportunistic behavior of the editor of ERP open source at their alliances' level. According to them, the editor of ERP open source has a double agenda and takes advantage of the open source community that supports the evolution of the ERP system open source. These firms emphasize that the ERP open source editor does not have sufficient in-house powers to develop and advance the ERP open source. A large part is done by the community. Thus, several modules are developed by the community and not the editor ERP open source. All companies A, B, C criticize the fact that the editor of ERP open source does not take account of its promises and commitments to its partners and run away from its responsibilities very often. They mention that the editor of ERP open source changes the rules of the contract (i.e., contract terms) all the time; as a result, several partners (i.e., IT service companies) opt out after 2 years. According to company A, the ERP open source editor is only concerned by the contributions of his or her partners and recurring revenues. The following few excerpts, verbatim, show the risk of opportunistic behavior of some ERP editors open source:

"Most of the new partners are naively abused, thinking that open source is filled only with nice people. On the other hand, most of the partners having withstood more than 2 years have no illusions about these promises and perform judgment in case by case".

"It derives most of its revenue via partners and their SME customers, the editor does not reinvests that money to meet the needs of its clients and partners, but spend it to fantasize its investors with business model with recurring revenue".

\subsection{Risk of Conflict}

The risk of conflict has been raised by the three partners in their alliances with ERP Editor open source. The risk of conflict is according to, our interviewees, very present in such an alliance. This can be caused by the opportunistic behavior of some publishers ERP open source. The change of contract clause, non-compliance are elements that can feed the frustration of partners; in other words, the tension in such a relationship. According to our respondents, their ERP open source editors do not consult them when making critical decisions concerning the evolution and direction of the project. So, they perceive that power sharing is not balanced. As per Company C, the ERP open source editor has changed its business model after he created a SaaS offer of ERP open source. Consequently, such an offer of service is seen as a conflict of interest for the partners. Providing a SaaS service, makes the editor of ERP open source a competitor for its partners. This has increased the apprehension among IT service companies' associates because, by doing so, the editor takes some of his partners' market share. The Company B criticizes the way in which the open ERP open source editor classifies its partners ranging from gold to bronze through money. Thus, this classification is not based on the values of functioning of open source communities i.e. on merit, but rather on the money paid by the partner upon accession.

The following few excerpts of the verbatim show tensions on relations between publishers ERP open source and their partners:

"The tensions are there, but if they grow to conflict, there'll just be a divorce and alternatives are not lacking for both parties".

"The risk of conflict is very strong and more likely".

"There is rather a sidelining of the majority of partners and a small number (3) of partners who are invited to the reflection on the development project".

"There is a risk of direct support for the best clients by the Publisher; there is also the SaaS offering in competition with those of the partners".

"All the promises are not kept".

"The editor should assume its deficiencies and integrate technical and functional improvements that come from the community. The editor only has a marginal competence to perform the integrations that a few successful partners do. Therefore, the editor is relatively not able to fully meet its partners technical support needs".

"A partner who will have spent 2 years to do a localization for a cost equivalent to US $\$ 200000$, would be placed behind, in the ranking of the partners, a partner from the owner's class that would be making a $\$ 20,000$ check to 
become Silver"

\subsection{Risk of Absorption}

The risk of absorption is the risk that a partner appropriates all the work of an alliance. This risk also occurs when a partner wants to shadow its partners by taking advantage of their work. Our respondents have all raised the risk of absorption issue. According to them, their open source ERP editors try to take advantage of the work of the Open Source Community. All companies (A, B, C) have raised the risk of absorption issue on their alliances with ERP open source editors.

"He, for example, ousted the authors of argentine and Spanish localizations modules to try to take the market over with paid valets".

"It is the current process undertaken by the ERP open source editor significantly associated from version to version".

\subsection{Risk of Non-Appropriation of the Partnership}

The risk of non-appropriation implies any risk relating to the problems of transfer of skills and those associated with the problems of transparency. This risk may be due to a problem of transparency. All companies (A, B, C) have derided the lack of transparency of the open source ERP editor. Thus, such a lack of transparency may unbalance the alliance in the sense that a partner is trying to produce an asymmetry of knowledge and skills. Thus, a lack of transparency can create tensions between the editors of ERP open source and their partners.

"The editor tries to close the platform by restricting access to the modules (with the latest version of the system) if not in possession of service contract".

"The Publisher restricts access to information to avoid easing debug's situations and thus disregarding their support. As a matter of fact, they have recently closed a very important FORUM".

\subsection{Risk of Divergence of Objectives}

The risk of divergence of goals occurs when an alliance partners stop sharing the same goals and vision. All companies (A, B, C) have raised this risk issue in their relationship with the ERP open source editor. Partners often diverge on several points with the ERP open source editor. They differ on the way editors spend the money collected during fundraising. In addition, they noted a divergence on how to manage the improvements made by the partners.

"Their goal has changed to solve their short-term accounts and satisfy their investors in the mid and long term. If the product is good or not, open or not, it becomes a marginal problem for them".

"The ERP open source editor offer themselves the monopoly over the commits on the core, even though it has a very limited pool of talented in-house developers".

\section{Discussion}

This study shows that IT service companies who collaborate with the editors of ERP systems open source are exposed to risks. They are exposed to several risks such as the risk of bifurcation, the risk of opportunistic behavior, the risk of conflict, the risk of absorption, the risk of non-appropriation, the risk of divergence of objectives (see figure 1). These results appear to be amazing, given the ethical and moral values of the open source communities. However, they reflect reality because more and more firms from private sector invest in the world of open source software and support the development of these open source software. It should be noted that editors of the ERP open source and computer services companies (from private sector) are companies who seek to increase their profits in the ERP software arena; a universe in which sharing and freebies are the main axes of conduct. This shows that, even in the world of open source software, there may be risks when a computer services company is working with an editor of ERP open source. These found risk factors converge with those already mentioned in the literature whenever there is a deal between two entities. As in any alliance, the risk of opportunistic behavior of a partner may hinder the sustainability of this alliance (Das \& Teng, 1996; Belal-Chomkolyan et al., 2008; Parkhe, 1993). Opportunistic behavior reduces the confidence of partners and may increase the risk of conflict, as noted by Zaheer et al. (1998) In short, these results converge with literature in respect of risks that could impede on a partnership relation: the risk of non-appropriation (Kale et al., 2000), the risk of absorption (Clarkson \& Sadowski, 1999), the risk of conflict (Zaheer et al., 1998), the risk of misunderstanding (Doz, 1996), the risk associated with issues of contribution and retribution (Brockhoff, 1992), the risk associated with the problems of costs (Brockhoff, 1992), the risk of defection (Nooteboom et al., 1997), the risk of opportunistic behavior (Parkhe, 1993), the risk of absorption (Clarkson \& Sadowski, 1999), the risk of divergent objectives (Clarkson \& Sadowski, 1999), etc. Thus, the probability of failure or split is very high in a partnership. The risk can play on trust, transparency, and the 
commitment of the partners. Risks are high in a relationship and more confidence decreases as well as transparency and commitment. And after Dahlander and Magnusson (2005), there are three types of relations between an open source community and a proactive business: 1) a symbiosis relationship; 2) a commensal relationship; 3) a parasite relationship. In the case of relations between ERP open source editor and their partners (i.e., related IT Services Companies), these relationships can be assimilated, in some respects, like parasitic relationships.

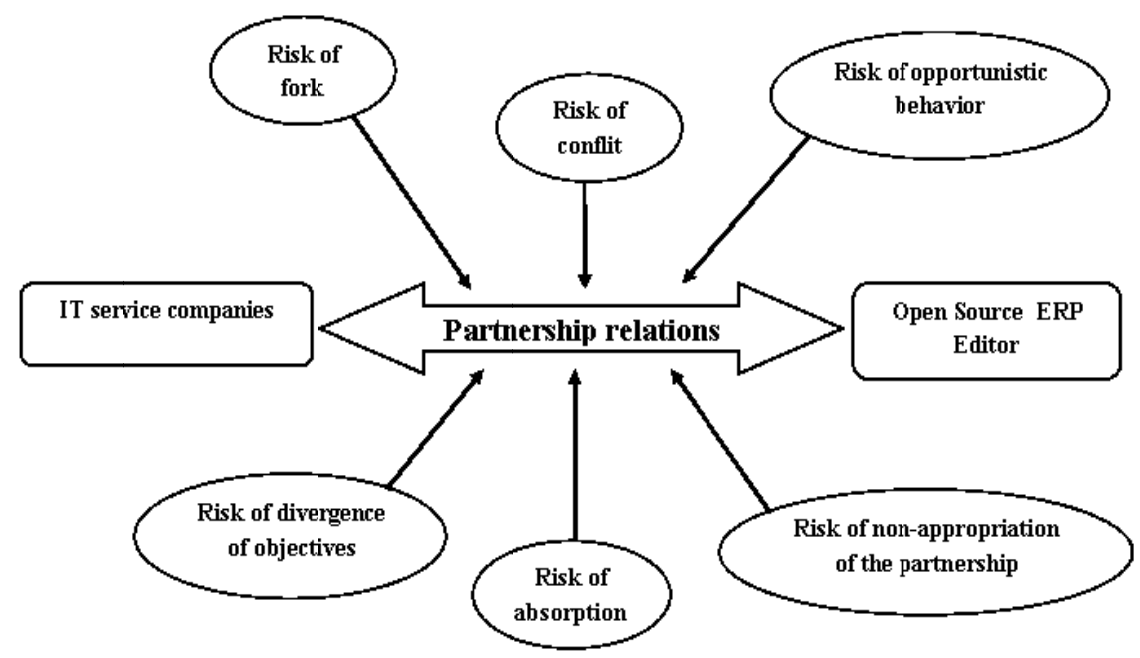

Figure 1. Potential risks in a partnership relation between the open source ERP editors and their partners (i.e., IT services companies)

\section{Conclusion}

According to Mark Driver, Research Vice President of Gartner, at least $80 \%$ of commercial software packages will contain open-source code (Brodkin, 2007). The expansion of open source software especially Open-Source ERP systems continue to grow in all areas. Several major firms in IT industry (such as IBM, HP, Dell, Google, etc.) support the development of open source software. Open source software have upset all the IT industry to the point that the majority of companies in the computer industry were obligated to follow by adapting their business models to the ERP Open Source systems. The ERP sector was upset recently by the emergence of the open ERP sources co-developed by the open source communities and other actors (for instance, IT firms and other private companies considered as editors). Dahlander and Magnusson (2005) had found three types relations between private companies and the free communities, namely the symbiosis, the commensal, and parasite relationships. In this study, we investigated the relationships between these stakeholders that support free software; in other words, the relations between ERP open source editors and their partners (IT companies). Through a case study, we found that many partners working with the ERP open source editors are exposed to several risks that could impede the continuity of a deal. This include the risk of bifurcation, risk of opportunistic behavior, risk of conflict, risk of absorption, risk of non-appropriation, and risk of divergence of objectives and vision (see figure 1).

This research has several limitations. One of the limitations comes from the methodological approach used: a case study approach. However, each method has its advantages and disadvantages, and the case study is no exception. It is more limited than the generalization's investigations. Hence, these results supported by three cases of partnership relations, cannot be generalized as relationships between ERP open source editors and their partners. The other limit is that we have only collected the performance of companies in computer business in regard to the relationship with their ERP open source editors and partners. We consider however that this research is an advance step towards the understanding of potential risk factors that may exist in the universe of open source software when two private companies come together to support the development and evolution of a IS/IT such as ERP open source system. Finally, future researches could focus more directly on risk factors in the relationship between ERP open source editors and other members of the community not involved in any partnership. Another interested research may be to examine the reasons for the bifurcations of the open source projects, as the fork is one of the major threats of the evolution of open source software. 


\section{References}

Aloini, D., Dulmin, R., \& Mininnoa, V. (2007). Risk management in ERP project introduction: review of the literature. Information \& Management, 44(6), 547-67. http://dx.doi.org/10.1016/j.im.2007.05.004

Besson, P. (1999). Les ERP à l'épreuve de l'organisation. Systèmes d'information et management, 4(4), 21-51.

Bitner, M. J. (1990). Evaluating Service Encounters: The Effects of Physical Surroundings and Employee Responses. Journal of Marketing, 54(April), 69-82. http://dx.doi.org/10.2307/1251871

Bonaccorsi, A., \& Rossi, C. (2006). Comparing motivations of individual programmers and firms to take part in the open source movement: From community to business. Knowledge, Technology \& Policy, 18(4), 40-64. http://dx.doi.org/10.1007/s12130-006-1003-9

Bouras, C., Kokkinos, V., \& Tseliou, G. (2012). Methodology for Public Administrators for Selecting between Open Source and Proprietary Software. Journal of Telematics and Informatics (to appear).

Brockhoff, K. (1992). R\&D cooperation between firms: a perceived transaction cost perspective. Management science, 38(4), 514-524. http://dx.doi.org/10.1287/mnsc.38.4.514

Brodkin, J. (2007). Open source impossible to avoid, Gartner says. Network World, retrieved from http://www.networkworld.com/news/2007/092007-open-source-unavoidable.html

Claybaugh, C. C., \& Srite, M. (2009). Factors Contributing to the Information Technology Editor-Client Relationship. Journal of Information Technology Theory and Application (JITTA), 10(2), 3.

Dahlander, L., \& Magnusson, M. G. (2005). Relationships between open source software companies and communities: Observations from Nordic firms. Research Policy, 34(4), 481-493. http://dx.doi.org/10.1016/j.respol.2005.02.003

Darke, P., Shanks, G., \& Broadbent, M. (1998). Successfully Completing Case Study Research: Combining Rigour, Relevance and Pragmatism. Information Systems Journal. 4(8), 273-289. http://dx.doi.org/10.1046/j.1365-2575.1998.00040.x

Das, T. K., \& Teng, B. S. (1996). Risk types and inter-firm alliance structures. Journal of Management Studies, 33(6), 827-843. http://dx.doi.org/10.1111/j.1467-6486.1996.tb00174.x

Doz, Y. L. (1996). The evolution of cooperation in strategic alliances: Initial conditions or learning process? Strategic management journal, 17, 55-83. http://dx.doi.org/10.1002/smj.4250171006

Eisenhardt, K. (1989). Building Theories from Case Study Research. Academic of Management Review, 14(4), $532-550$.

Hagedoorn, J., \& Sadowski, B. (1999). The transition from strategic technology alliances to mergers and acquisitions: an exploratory study. Journal of management studies, 36(1), 87-107. http://dx.doi.org/10.1111/1467-6486.00127

Halilem, N., \& Diop, B. (2008). La stratégie proactive d'intégration du libre au sein des entreprises de logiciels propriétaires: les axes de gestion. article présenté à la conférence de l'association canadienne des sciences de l'administration (ACSA), Halifax, 24-27 mai 2008.

Heeks, R. (2002). Information systems and developing countries: Failure, success, and local improvisations. The Information Society, 18(2), 101-112. http://dx.doi.org/10.1080/01972240290075039

Huang, S. M., \& Chang, I. C. (2004). Assessing risk in ERP projects: identify and prioritize the factors. Industrial Management \& Data Systems, 104(8), 681-688. http://dx.doi.org/10.1108/02635570410561672

Kale, P., Singh, H., \& Perlmutter, H. (2000). Learning and protection of proprietary assets in strategic alliances: Building relational capital. Strategic Management Journal, 21(3), 217-237. http://dx.doi.org/10.1002/(SICI)1097-0266(200003)21:3<217::AID-SMJ95>3.0.CO;2-Y

Lerner, J., \& Tirole, J. (2003). Some simple economics of open source. The journal of industrial economics, 50(2), 197-234. http://dx.doi.org/10.1111/1467-6451.00174

Mabert, V. A., Soni, A., \& Venkataramanan, M. A. (2000) Enterprise Resource Planning Survey of U.S. Manufacturing Firms. Production and Inventory Management Journal, 41(2), 52-58.

Metaxiotis, K. (2009). Exploring the rationales for ERP and knowledge management integration in SMEs. Journal of Enterprise Information Management, 22(1/2), 51-62. http://dx.doi.org/10.1108/17410390910922822 
Miles, M., \& Huberman, A. (1994). In C. C. Ragin (Ed.), Qualitative Data Analysis: An expanded sourcebook (2nd ed.). Thousand Oaks, CA: Sage Publications.

Miller, D., (1992). Environmental Fit versus Internal Fit. Organization Science, 3(2), 159-178. http://dx.doi.org/10.1287/orsc.3.2.159

Motwani, J., Subramanian, R., \& Gopalakrishna, P. (2005). Critical Factors for Successful ERP Implementation: Exploratory Findings from four case studies. Computers in Industry, 56(6), 529-544. http://dx.doi.org/10.1016/j.compind.2005.02.005

Nooteboom, B., Berger, H., \& Noorderhaven, N. G. (1997). Effects of Trust And Governance On Relational Risk. Academy Management Journal, 40(2), 308-338. http://dx.doi.org/10.2307/256885

Parkhe, A. (1993). Strategic Alliances Structuring: A Game Theoretic And Transaction Cost Examination Of Interfirm Cooperation. Academy Management Journal, 36(4), 794-829. http://dx.doi.org/10.2307/256759

Poba, N. P., Raymond, L., \& Fabi, B. (2008). Adoption and risk of ERP systems in manufacturing SMEs: a positivist case study. Business Process Management Journal, 14(4), 530-550. http://dx.doi.org/10.1108/14637150810888064

Sowe, S. K., Stamelos, I., \& Angelis, L. (2008). Understanding knowledge sharing activities in free/open source software projects: An empirical study. Journal of Systems and Software, 81(3), 431-446. http://dx.doi.org/10.1016/j.jss.2007.03.086

Von Krogh, G., \& Spaeth, S. (2007). The open source software phenomenon: Characteristics that promote research. The Journal of Strategic Information Systems, 16(3), 236-253. http://dx.doi.org/10.1016/j.jsis.2007.06.001

West, J. (2003). How open is open enough?: Melding proprietary and open source platform strategies. Research Policy, 32(7), 1259-1285. http://dx.doi.org/10.1016/S0048-7333(03)00052-0

Williamson, O. E. (1991). Comparative Economic Organization: The analysis of discrete Structural Alternatives. Administrative Science Quarterly, 36, 269-296. http://dx.doi.org/10.2307/2393356

Xue, Y., Liang, H., Boulton, W. R., \& Snyder, C. A. (2005). ERP implementation failures in China: Case studies with implications for ERP editors. International Journal of Production Economics, 97(3), 279-295. http://dx.doi.org/10.1016/j.ijpe.2004.07.008

Yin, R. K. (2009). Case Study Research: Design and Methods (4th ed.). California: Sage Publications.

Young, Y. C., \& Wiersema, M. (1999). Strategic Flexibility In Information Technology Alliances: The Influence Of Transaction Cost Economics And Social Exchange Theory. Organization Science, 10(4), 439-459. http://dx.doi.org/10.1287/orsc.10.4.439

Zaheer, A., McEvily, B., \& Perone, V. (1998). Does trust matter? Exploring the effect of inter organizational and interpersonal trust on performance. Organization Science, 9, 141-159. http://dx.doi.org/10.1287/orsc.9.2.141

\section{Copyrights}

Copyright for this article is retained by the author(s), with first publication rights granted to the journal.

This is an open-access article distributed under the terms and conditions of the Creative Commons Attribution license (http://creativecommons.org/licenses/by/3.0/). 